Textures and Microstructures, 1988, Vols. 8 \& 9, pp. 55-75

Reprints available directly from the publisher

Photocopying permitted by license only

(C) 1988 Gordon and Breach Science Publishers Inc.

Printed in the United Kingdom

\title{
Fifty Years Textures in Research and Practice
}

\author{
H. J. BUNGE \\ Department of Physical Metallurgy, Technical University of Clausthal, FRG
}

(Received February 12, 1988)

Dedicated to the memory of Professor Günter Wassermann

The orientation distribution or texture of the crystallites is one of the most important structural parameters of polycrystalline materials. Texture studies were carried out for more than fifty years. This branch of materials science, first established by G. Wassermann in 1939 by his monograph "Texturen metallischer Werkstoffe," has now developed into a quantitative science based mainly on measurements by X-ray, neutron and electron diffraction. A mathematical theory of textures has evolved mainly in the last twenty years. The extension of interest from basic metals to all kinds of crystalline materials is one of the present features. Concludingly, the future development in the field of textures may be extrapolated.

\section{INTRODUCTION}

It is now nearly fifty years since Günter Wassermann, in 1939, published his first monograph "Texturen metallischer Werkstoffe." Although preferred orientations of crystals in polycrystalline aggregates were considered before, even before the discovery of X-ray diffraction in 1912, Wassermann's book can be considered the first distinct manifestation of this new branch of materials science which is now very well established in fundamental research as well as in industrial practice. Within the last two decades the quantitative mathematical treatment of the texture problems has been widely developed on the one hand and, on the other end of the scale, 
on-line texture measurement has found entrance in industrial production processes.

Fifty years ago the importance of texture as a basic structural parameter of all polycrystalline materials had not yet been generally recognized. In the foreword of this book, Wassermann concluded that, at that time, many metallurgists were still reserved against everything connected with metal crystals.

Meanwhile, this situation has changed completely. Today, it is nearly a commonplace that the properties of crystalline materials can only be understood on the basis of their crystal structure and hence, that crystal orientation is a decisive parameter for all polycrystalline materials. Research and development in the field of textures has experienced a considerable impetus especially after the international conference in Tokyo 1981. Some ten books on texture have since been published. The series of international conferences started by Wassermann in 1969 in Clausthal is now well established, their proceedings continuously increasing in volume, and most of metallurgical societies established working groups or subcommittees on textures. Last not least the journal "Textures and Microstructures" presents this special volume, dedicated to the memory of Günter Wassermann, which provides at the same time a good survey of the present state of the art in the field of textures in fundamental research as well as in industrial practice.

\section{TEXTURE AND GENERALIZED TEXTURAL QUANTITIES}

Texture is one of the fundamental structural parameters of all polycrystalline solid matter. Defined in the classical sense, texture is the orientation distribution function (ODF) of the crystallites. Its importance as a structural parameter results from the anisotropy of most of the physical properties of crystals. The anisotropies of differently oriented neighbouring crystals give rise to a microinhomogeneity which is a fundamental structural property of all polycrystalline matter. Secondly, if the texture is not random-and strictly speaking it is never completely random-then the microscopic anisotropies of the crystals are not completely averaged out so that a macroscopic anisotropy results. Hence, polycrystalline 
materials must generally be considered as microinhomogeneous anisotropic media, the properties of which depend on the texture.

The classical definition of the texture as the orientation distribution function of the crystals contains only angular variables describing the orientation of crystal axes with respect to some appropriately chosen reference directions in the material. It does not contain any information about the spatial coordinates of the crystals, their sizes or their neighbourship relations. Considered on the basis of the classical texture a polycrystalline material is thus assumed to be macroscopically homogeneous (on a scale large compared with grain size) and the neighbourhood relationships of crystals of different orientation are random.

This classical definition of texture must be considered as the first approximation of a long series of "generalized textural quantities" which combine information about crystal orientation (angular coordinates) with information of crystal position (spatial coordinates). Examples of such generalized textural quantities are the local textures in texturally inhomogeneous materials, grain sizeorientation distribution functions needed in the theory of continuous grain growth, misorientation distribution functions or orientation correlation functions in grain and phase boundaries, shape distribution functions of crystallites or of phase particles in multiphase materials, e.g. lamellae-orientation distribution functions of eutectics. The most general aspect of such "generalized textural quantities" are $n$-point orientation correlation functions (Kröner, 1974) which define the probability of finding simultaneously the crystal orientations $g_{0} g_{1} g_{2} \ldots g_{n}$ in points which are apart from each other by the vectorial distances $r_{1} r_{2}, \ldots, r_{n}$.

A still more complete structural description of a polycrystalline material is only possible by specifying its individual structural function $g(r)$ i.e. by specifying the crystal orientation $g$ in any point $r$ of the material. This is, however, no longer a statistical description of the polycrystalline structure as was presumed in the definition of the "generalized textural quantities."

In the classical definition of the texture, the ODF, as well as in the definition of the generalized textural quantities the constitutive crystals were tacidly assumed to be ideal crystals (except for their finite size). This is, of course, generally not the case, not even in the most perfect materials. In real materials the crystallites contain 
lattice defects such as vacancies, interstitial atoms, impurities, dislocations and dislocation substructures, stacking faults, internal stresses or directional order. As far as these crystal imperfections are independent of crystal orientation, the concept of the texture in the classical sense as well as the generalized textural quantities can similarly be applied to imperfect crystals as well, which can be considered as "ideal" crystals with modified properties.

This concept becomes, however, questionable in the presence of dislocation substructures such as subgrain or cell structures. In this case crystal orientation of the whole "crystallite" is not strictly defined. Neighbouring subcells may have orientation differences in the order of magnitude of a few degrees. The orientation $g$ of a crystallite then becomes a somewhat "diffuse" quantity which may better be described by a narrow distribution function. In this case the concept of texture may be better applied to subgrains or cells rather than to the crystallites. During plastic deformation, the misorientation of neighbouring subgrains or cells increases, leading finally to new structural units replacing the original crystals (which were formed for example by recrystallization prior to deformation). This "splitting" effect does not matter, however, in all those textural parameters which are defined by the volume fraction such as the classical ODF which is the orientation distribution by volume. It is, however, essential in all quantities defined on the basis of individual crystallites such as for instance the ODF by number.

The imperfect nature of the crystals is especially important if the imperfections are orientation dependent. It has repeatedly been found for example that dislocation substructures of deformed materials are orientation dependent (see e.g. Gil Sevillano et al. 1980). The same applies also to internal stresses of crystallites in polycrystalline materials as well as to directional ordering e.g. by magnetic annealing. In all these cases the concept of texture or generalized textural quantities may nevertheless be applied in a modified way. The averages of properties calculated with the textural quantities as weighting functions must then, however, be based on crystals the properties of which are also orientation dependent. In the case of internal stresses for instance an orientation dependent stress tensor $\sigma_{i j}(g)$ (internal stresses of second kind) may be defined which is the basis for the calculation of X-ray line 
shift and line broadening respectively. In the case of directional ordering strictly speaking each crystallite has its own crystal structure (taking atomic order into account) depending on its orientation.

\section{DEVELOPMENT OF QUANTITATIVE TEXTURE ANALYSIS}

The first texture investigations can be dated back to immediately after the discovery of X-ray diffraction by Friedrich Knipping and v. Laue in 1912 when Knipping interpreted the features of the diffraction pattern of platinum by an anisotropic distribution of the crystallites. In 1924 Wever evaluated the intensity distribution of Debye-Scherrer patterns taken in different sample orientations in terms of qualitative pole figures. On the basis of these photographic pole figures, texture development in metals was already systematically studied from a fundamental point of view but also with respect to the technological importance of textures. When Wassermann in 1939 published his fundamental monograph "Texturen metallischer Werkstoffe" texture formation due to primary crystallization, to deformation, and to recrystallization in most of the important metallic materials had already been studied and physical and technological properties of these materials were considered on the basis of their respective textures.

A more quantitative texture determination became possible when Decker, Asp and Harker in 1948 proposed a method for pole figure determination by an X-ray counter diffractometer. Together with the method proposed by Schulz in 1949 it was then possible to measure complete quantitative pole figures for several reflections $(h k l)$. The interpretation of these quantitative pole figures was, however, still qualitative. The peaks of the pole density distributions were interpreted in terms of ideal orientations $\{h k l\}\langle u v w\rangle$ where $\{h k l\}$ is the lattice plane parallel to the rolling plane and $\langle u v w\rangle$ is the crystal direction parallel to rolling direction. If several ideal orientations were present, their volume fractions could be estimated and also spread ranges could be included. Ideal orientations are texture components represented by a point in an orientation space. The concept of "ideal texture components" was also generalized by introducing one-dimensional components i.e. fibre 
components and restricted fibre components by Grewen and Wassermann (1955). On this basis the fundamentals of texture formation in most metals and alloys were comprehensively developed and were summarized in Wassermann's second monograph "Texturen metallischer Werkstoffe" published in 1962 together with his co-worker J. Grewen. This second edition had already increased in volume from 194 pages in 1939 to 808 pages, showing the great theoretical and technological importance of texture studies.

The interpretation of pole figures in terms of ideal orientations becomes more and more difficult the higher the number of orientations is. If finally the texture is to be considered as a continuous distribution function, interpretation in terms of individual orientations is no longer possible. Generally a pole figure is a two-dimensional "projection" of the three-dimensional orientation distribution function. Using mathematical methods, the ODF can be calculated numercially if a sufficient number of pole figures are known. The solution of this problem, known as pole figure inversion, was at first achieved using a series expansion by orthogonal functions, Bunge (1965), Roe (1965). An alternative method due Williams (1968) and Ruer and Baro (1977), known today as vector method, uses a discretization of the continuous ODF. A probabilistic method is due to Imhof (1977) and the mathematically most elegant solution of the problem was given by Matthies in 1979 in the form of an integral transformation. Due to the general properties of the orthogonal function systems the series expansion method (harmonic method) proved as the most versatile one which found a widespread application. A survey of the mathematical methods of texture analysis was given by Bunge $(1969,1982)$. A short introduction is contained in the proceedings of a summer school edited by Bunge and Esling (1982).

On the basis of the mathematical analysis of pole figures it was for the first time possible to check the accuracy of pole figure measurements (Bunge, 1966). It turned out that experimental errors in the range of $30-50 \%$ were not seldom (Schläfer, 1968). Hence, the precision of pole figure measurements had to be improved. This was achieved by the use of a new generation of step-motor operated, computer controlled texture goniomters on the one hand (see e.g. Puch et al., 1984) and by the use of neutron diffraction instead of X-ray diffraction (Bunge, Tobisch, 1968). 
In the same paper giving the integral transformation formula, Matthies (1979) pointed out that the superposition of $(h k l)$ and $(\bar{h} \bar{l})$ pole figures due to Friedel's law leads to a falsification of the ODF which expresses itself in the extinction of the odd terms of the series expansion, thus giving rise to ghost peaks in the so called "reduced" ODF, which had already been observed experimentally by Matsuo et al. (1972). Matthies' work provoked a lot of activities aiming at the recognition or reduction of ghost phenomena. Some of this work was summarized by Matthies (1982) who also prepared "ghost charts" for virtually all possible texture components (Matthies et al., 1987).

Generally, superpositions of this kind are due to all crystal symmetries of second kind (Inversion operations cannot be dealt with in the Euler space which "knows" only rotations). These superpositions can be classified into three groups, depending on the crystal symmetry group (Bunge, Esling, Muller, 1981). The difficulties due to crystal symmetries of second kind can completely be removed by representing the ODF in the space of general orthogonal transformations (rotations plus inversions) instead of the space of rotations only (Esling, Bunge, Muller, 1980). On the basis of the orthogonal transformation space, the classification of texture symmetry types given by Weissenberg (1922) was generalized including "non-conventional" symmetries. The comprehensive symmetry description of textures thus requires black-white point groups (see e.g. Bunge, Esling, 1985).

The ambiguity of ODF calculation due to pole figure superposition can be overcome or can at least be reduced by taking the positivity condition of the ODF into account. If the texture contains zero ranges, the ambiguity can be virtually completely removed (Bunge, Esling, 1979). A more general method (Dahms, Bunge, $1988 \mathrm{a}, \mathrm{b}$ ) allows to find several possible solutions within the ambiguity range. A rigorous solution enforcing positivity was also given by van Houtte (1983) defining the ODF as the square of another distribution function.

Several methods were also proposed which select a specific solution out of the ambiguity range e.g. the method of model functions (Lücke et al., 1981) which assumes a specific shape of the texture function in the vincinity of its peaks. Matthies and Vinel (1982) developed an inversion method (WIMV) on the assumptions 
of Williams and Imhof. Thereby they employed a conditional ghost correction assuming the sharpest possible peaks besides the highest random texture component. A somehow opposite assumption was proposed by Liang and Wang (1988) who favorized the flattest possible solution.

The ambiguity due to Friedel's law considered first by Matthies can be removed by using anomalous scattering (Bunge, Esling, 1981). This does, however, not allow to remove the ambiguities due to crystal symmetries of second kind.

With these methods it is now possible to calculate the true ODF by pole figure inversion within an accuracy in the range of, say, $1 \%$ if a sufficient number of pole figures are available with a similar accuracy, provided the ambiguity range of the solution is not larger than that. Thereby it is one of the advantages of the series expansion method that it provides a least square error minimisation of the experimental pole figure errors. Another advantage of this method due to the orthogonal nature of the used functions is its rapid convergence and hence comparatively short computer times (Esling et al., 1987). One of the earlier disadvantages of the series expansion method was its neglection of the positivity condition of the pole figures. Hence, a somewhat larger number of pole figures was needed compared for example with the vector method in order to solve the pole figure inversion problem. This disadvantage can, however, easily be overcome by making full use of the positivity in all pole figures, including the not measured ones (Dahms, Bunge this volume). Hence, the series expansion method may now be looked upon as the most versatile and at the same time most economic one among the pole figure inversion procedures.

The series expansion method was developed independently in two different terminologies Bunge (1965), Roe (1965) which have since been frequently used. A "translation" between the two terminologies was given by Esling et al. (1982). In order to make comparison of results easier the use of the first one of these terminologies was recently recommended by an international board (Wenk et al., 1988).

Orientation distribution functions are most frequently expressed in terms of Euler angles, the values of which are represented as Cartesian coordinates. This representation is degenerated at $\Phi=0$ and $\Phi=180$. In these planes an orientation is represented by a line 
rather than a point. In order to avoid this degeneration it was proposed to represent const- $\varphi_{1}$ or const- $\varphi_{2}$ sections by polar coordinates (Wenk and Kocks, 1986). However, this gives rise to a non-unique singular point at $\Phi=0$. A not degenerated and unique representation is obtained by representing $\varphi_{1}+\varphi_{2}$ or $\varphi_{1}-\varphi_{2}$ sections in polar coordinates (Bunge 1988, Matthies, 1988).

Summarizing all these results, it can be concluded that the texture in the classical sense is now available as a structural parameter of polycrystals with an accuracy which allows a theoretical treatment of the properties of polycrystals by thorough mathematical models (see also Bunge, 1987a).

\section{MATHEMATICAL MODELLING OF TEXTURED POLYCRYSTALLINE SOLIDS}

Three different kinds of theories may be distinguished. The first kind of theories relates the macroscopic mean values of various physical properties to the single crystal properties and the texture. These mean values are uniquely determined by the texture alone if there are no interactions between the crystals (This applies in a good approximation to the magnetic anisotropy in saturation). Generally, however, there are grain interactions. Then the mean values depend not only on the texture but also on further generalized textural quantities such as orientation correlation functions. In these cases the texture alone allows only the calculation of upper and lower bounds (e.g. the Voigt and the Reuss approximation for the elastic properties, ref. Bunge, 1968). Higher order approximations (e.g. Kröner, 1958, Morris, 1970) require, at least implicitly, orientation correlation functions. Besides the macroscopic properties of the polycrystalline material also their microinhomogeneity is of interest for example if the dispersion of sound waves propagating in a polycrystalline material are considered (e.g. Hirsekorn, 1987).

A second and virtually even more important class of theories is concerned with texture formation or texture change due to physical processes occurring in the material. Such processes are for instance:

Primary crystallization (from non-crystalline state e.g. the melt, a solution, or an amorphous solid) 
Plastic deformation

Recrystallization

Phase transformation

Rigid rotation (e.g. sedimentation of particles or alignment in a magnetic field)

Quantitative theories of texture formation by plastic deformation are mainly based on the assumption of minimum deformation work for each crystallite proposed by Taylor (1938). Averaged over all crystallites within the concept of the classical texture, this leads to the second Taylor assumption of homogeneous deformation as an upper bound. A true constant stress approximation (lower bound theory) comparable to the Reuss approximation is not possible since only discrete stresses states can occur as was shown by Bishop and Hill (1951). The Taylor-Bishop-Hill theory has a unique solution for the yield stress but not for the orientation change. Hence, different averaging assumptions can be made which then lead to unique flow fields in the case of axially symmetric deformation (Chin, 1969) and three-axial deformation (Bunge 1970). The flow field can be described by a differential equation (Clement and Coulomb, 1979), which can also be expressed in terms of the series expansion coefficients (Bunge, Esling, 1984) and can thus be integrated numerically (Klein, Esling, Bunge, 1987). The texture development from any starting texture is thus obtained for a given deformation path. Model calculations carried out on this basis generally yield the correct texture type but the resulting textures are much too sharp (e.g. Bunge, Leffers, 1971). This seems to be due to the microinhomogeneity of deformation which can be taken into account by random stresses (Leffers 1968) or by considering the non-unique solution of the Taylor theory (Bunge, 1987b). The original Taylor theory was improved later on mainly along two major lines, i.e. improving the assumptions describing single crystal behaviour as well as those taking grain interaction into account. A more realistic description of single crystal deformation for example allows for anisotropic strain hardening, for strain rate sensitivity (Canova and Kocks, 1984) or for the grain size and shape (Bunge et al., 1985). The consideration of grain interaction is much more difficult and, in principle, it requires the knowledge of orientation correlation functions. Since these are in general not known a random correlation is implicitly assumed. Kröner (1961) proposed 
elastic accommodation of the grain misfit whereas Berveiller et al. (1981) assumed elasto-plastic accommodation. Abe and Nagaki (1981) considered variable accommodation conditions. Improved results were especially obtained with one of the relaxed constrained models proposed by Honeff and Mecking (1978). The Taylor theory as well as its improvements in principle consider plastic deformation by slip only (including crystallographic slip as well as pencil glide). The contribution of twinning was considered for the first time by Chin et al. (1969) (see also Gil Sevillano et al., 1980). Orientation distribution functions of the twins themselves were determined by Nauer and Bunge (1988).

Modelling of recrystallization texture formation is much more difficult since the underlying processes, nucleation and grain growth, may depend on many unknown structural parameters. It is then helpful to consider two different orientation distribution functions of the crystallites, i.e. that by the volume fraction and that by the number fraction (Bunge, 1967). This allows in principle to seperate the contribution of oriented nucleation (Burgers, 1931) and oriented growth (Beck 1951) to recrystallization texture formation (Bleck, Bunge, 1981). Although very many investigations were carried out in order to understand nucleation processes (ref. e.g. Doherty, 1978) or grain boundary migration (ref. Haessner and Hofmann, 1978) this has not yet allowed to describe the orientation dependence of these two fundamental processes in terms of orientation distribution functions. Orientation distribution functions of nuclei measured by electron diffraction were for the first time obtained by Plege (1986). On this basis a simple model of recrystallization texture formation including the orientation dependence of nucleation and boundary migration was proposed by Bunge and Plege (1986).

The situation is easier in the case of continuous grain growth where only the orientation dependence of grain boundary energy and mobility is to be considered. At first a rather simple model was proposed by Novikov (1976). More detailed models were proposed by Abbruzzese and Lücke (1986) in a numerical form and by Bunge and Dahlem (1986) giving a partly analytical solution of the growth equation.

Texture transformation due to phase transformation can easily be modelled in terms of the series expansion coefficients of the ODF if 
the orientation relationship between matrix phase and transformed phase is known and if no variant selection (symmetry braking) occurs in the matrix phase (Bunge, 1969). It has, however, been shown that this latter condition is generally not fulfilled (Davies, Bateman 1981). A more realistic model has to include variant selection (Bunge, Humbert, Welch, 1983). Up to now, variant selection functions are, however, not yet sufficiently known which presently still restricts the applicability of this theory.

Texture formation due to rigid rotation has been reviewed by Örtel (1985) with respect to geological materials with anisotropic shape of particles. The textures due to powder compaction were investigated for example by Brokmeier (1983). The magnetic field alignment of powder particles of hard-magnetic materials is a usual technological practice (e.g. Heimke, 1976). Nevertheless quantitative theories are not yet available. An especially interesting variant of rigid rotation is the rotation of small spheres on a substrate by diffusion as described for example by Maurer (this volume).

Finally, a third kind of theories based on the ODF may be distinguished. These are theories which relate other polycrystal properties to the corresponding experimental measurements e.g. $\mathrm{X}$-ray integrated peak intensities to volume fractions of phases (X-ray phase analysis) or the line shift to internal stresses (X-ray stress analysis). The corresponding equations contain the ODF. The knowledge of the ODF is thus a prerequisite for a correct evaluation of the measured data as described for example by Brakman (1987) or Barral et al. (1987) for stress analysis or Bunge et al. (in print) for phase analysis.

\section{GENERALIZED TEXTURAL QUANTITIES}

As was already mentioned above, several kinds of generalized textural quantities have attracted interest in recent years. The most general and statistically complete description of a single phase polycrystal is that by $n$-point correlation functions given by Kröner (1974). The experimental determination as well as the mathematical handling of these functions is, however, rather difficult. A first attempt to determine such functions was made by Haessner (1981) in the form of orientation topography. A mathematical treatment of 
two-point correlation functions was recently given by Adams $e t$ al. (1987) and by Morris et al. (1988). The misorientation across grain or phase boundaries is more easy to treat since no $r$-dependence occurs in this function (Plege, 1986, Bunge, Weiland, 1988). The experimental determination of misorientation or correlation functions requires localized orientation measurements. With the usual grain sizes this is only possible by electron diffraction. Selected area electron diffraction was used for texture measurements by Lücke $e t$ al. (1964) and Haessner et al. (1966). In the conventional form this method has an angular resolving power in the range of $5-10^{\circ}$ which can only be improved by either measuring the intensities of diffraction spots (v. Heimendahl, 1970) or by a sophisticated method combining two or three dark field images (Plege, 1983). It has been shown recently that the preference of low index orientations may strongly falsify the so obtained texture (Schwarzer and Weiland, 1988). The angular errors of selected area diffraction are even worse when correlation functions are to be determined. The latter ones really require orientation measurements by Kikuchi patterns in transmission or by chanelling or backscattering patterns in reflection. The evaluation of such diagrams can be carried out to an accuracy in the order of $1^{\circ}$ and orientation differences of neighbouring crystals can be obtained even much better. The rational evaluation of such diagrams requires computer programs (Venables and Bin-Jaya, 1977) and a rational measurement procedure must be "on-line" (Schwarzer, Weiland, 1984). It has also been suggested to fully automatize the measurement by using methods of image analysis (Mori, Ishida, Onoe, 1982). This way, it is, however, still extremely difficult to avoid ambiguities in the calculated orientation.

Textures of multiphase materials are becoming increasingly interesting. Each phase has its own texture which can-in principle-be determined in the same way as single phase textures (see e.g. Bunge, 1985a). Nevertheless, several experimental difficulties may arise which require special techniques:

- If the number of phases in a material increases then peak superposition will become increasingly abundant. In order to separate the peaks, texture measurement using position sensitive detectors (Bunge, Wenk, Pannetier, 1988) or energy dispersive methods (Bordas et al., 1977) or the time-of-flight method in the case of neutron diffraction (Feldman 1986) is then required which 
allow peak separation by line profile analysis (Jansen, Schäfer, Will, 1986). The remaining coincidences can be separated by a least squares analysis along with the ODF-calculation (Bunge 1969, Dahms, Bunge, 1987). This latter method can be applied to single phase as well as to polyphase superpositions.

- An extreme case of line superposition occurs in phases having very similar diffraction diagrams such as ferrite and martensite. This can only be solved by individual texture measurements by electron diffraction in the two phases separately (Weiland, Schwarzer, 1986).

- An interesting case is texture measurement in phases which are contained in the sample only in very small volume fractions. It has been shown that this is possible using neutron diffraction. The texture of $0.1 \mathrm{Vol} . \% \mathrm{Cu}$ in an Al-matrix can easily be measured (Brokmeier, Böcker, Bunge, 1988).

- A principal difficulty arises in polyphase materials when the phases have anisotropic shapes (like lamellae) or are anisotropically arranged. In this case $\mathrm{X}$-ray intensity measurements may be strongly modified by anisotropic absorption (Bunge, Liu, Hanneforth, 1987). Since this effect does virtually not occur in neutron diffraction, multiphase textures should be measured by neutrons.

Increasing attention has also been paid to inhomogeneities of textures (see e.g. Bunge, 1982). It could be shown that different components of the rolling texture of steels are contained in different regions in the deformed structure (Kern, 1984). An elegant method to visualize texture inhomogeneities is $\mathrm{X}$-ray texture topography (Born, 1979). In optically anisotropic metals, such as titanium, texture topography can also be carried out by polarization optical methods (Bunge, Nauer-Gerhardt, 1980). Texture topography allows for example to reconstruct surface reliefs of a sample due to plastic deformation after they had been flattened out. Another important texture inhomogeneity is that of shear bands which can also be visualized by polarization optics in titanium.

Local textures in small areas like shear bands can be determined completely by pole figure measurements using electron diffraction as suggested by Schwarzer (1982) and Humphreys (1983). In order to obtain quantitative pole figures, the intensity corrections must be taken properly into account. Furthermore, the measurement can be fully automatized and computer operated (Schwarzer, 1983). The electron microscope can thus be used as an "electron texture goniometer" similar to X-ray or neutron texture goniometers. 


\section{ACTUAL PROBLEMS IN TEXTURE ANALYSIS}

Although textures have been studied intensively and successfully for more than eighty years a conspicuous increase of interest in this field of work can be observed during the last decade. This may be due to several reasons:

The increased accuracy of ODF calculations allowed for and also required mathematical model calculations of texture problems. Automation and computerization strongly facilitated texture measurements. New experimental methods allowed generalized textural quantities to be determined. And-last but not least-the technological interest in texture has increased considerably (see e.g. Chin and Gould, 1984, Bunge, 1985b, Merchant and Morris, 1985). This is certainly due to the increased accuracy of property control in technological materials by precisely controlling all other structural parameters. The variation range of materials properties due to uncontrolled texture variations is often in the range of $50 \%$ to a factor of 2. As soon as all other material parameters can be controlled better than that, texture then becomes the limiting parameter. Consequently, on-line texture measurement is today being incorporated in material production lines (Kopineck, 1986). Texture in the classical sense is defined by crystal orientation and also all the mentioned generalized textural quantities somehow contain crystal orientation. Hence, "texture" (in the definition used here) only applies to crystalline materials. On the other hand, however, it applies in a rather similar way to all crystalline materials, be they "natural" as the geological materials or artificial as technological materials and within the latter group textures may be considered in metals, nonmetallic anorganic materials or crystalline (or at least partly crystalline) polymers. In fact, microscopical texture studies in rocks and minerals were carried long before the discovery of X-ray diffraction (see e.g. Sander, 1930). Texture studies in polymer fibres were among the first X-ray texture studies (Gonell, Kratky, 1931) and the method of ODF-calculation was developed simultaneously in metals (Bunge, 1965) and polymers (Roe, 1965). Nevertheless, the vast majority of quantitative texture studies was carried out in metals. This also applies to the development of ODF analysis. From a methodical point of view, the main differences in texture analysis are the crystal symmetry (32 point symmetry groups, or with normal diffraction 12 Laue groups) and 
the sample symmetry (e.g. axial symmetry of fibres or orthorhombic symmetry of sheet). The space group, crystal structure or chemical nature of the material are unimportant. (There is, of course, some influence of the size of the unit cell.) Accordingly, the majority of all texture studies were carried out in the technologically important cubic metals with orthorhombic sheet symmetry. One aspect to be observed in the last years is, however, the continuously widening interest in other materials particularly geological materials (see e.g. Wenk, 1985, Ord, 1988, Quade this volume, Drechsler et al., this volume) but also ceramic materials (Chen, Bowman, 1988). Within the group of metals also lower symmetry metals such as the tetragonal tin (Dahms, Bunge, 1988) or intermetallic phases (Dahms, Bunge, 1986) were studied.

A survey on the present state of the art in the field of textures is contained in the contributions in the present volume dedicated to the memory of Günter Wassermann whose name has been the most prominent one in this field of work for more than fifty years.

\section{CONCLUSIONS}

With the development of the field of textures in the last fifty years in mind, some conclusions for the future development may be drawn. Also in the future, the majority of all technological materials will be polycrystalline. This holds for the classical materials as well as for most of the new" materials" which are presently being developed. Hence, texture studies will be needed in order to optimize these materials properties. Some of these materials have much more complicated crystal structures, lower symmetries and higher anisotropies than the classical metallic materials, hence, in all these case textures will even be more important than in the classical metals. The large field of quantitative texture studies in geological materials is still at its beginning. It can be taken for sure, that an increased accuracy of texture measurements (increased by one or two orders of magnitude) will allow to draw much more precise conclusions on the history of rocks and on the rock-forming mechanisms. For these studies large numbers of samples will have to be studied, thus requiring further development of fast, routine texture analysis. As was mentioned above, the texture forming solid 
state processes such as crystallization, plastic deformation, recrystallization, phase transformation and others are still far from being sufficiently understood. They are, however, the basis of "tailoring" materials with predetermined properties. The systematic use of anisotropic materials for applications with anisotropic application profiles (such as transformer core sheet materials) is still in the future. In this connection, on-line texture measurement in industrial production lines may find much wider use. New and improved methods of texture measurement may be expected. Quantitative texture measurement by electron diffraction must still be improved especially in order to measure generalized textural quantities such as correlation functions. Synchrotron radiation bears the potential of providing texture analysis with an angular resolving power increased by several orders of magnitude. As a rule, the increase of experimental accuracy by an order of magnitude generally reveals completely new effects. Hence, this is also to be expected for synchrotron texture measurements. The complete collection of diffraction data can still be improved. The classical texture measurements were carried out with a "point detector." Today linear position sensitive detectors are being introduced and even twodimensional detectors are now available (see e.g. Vergamini and Wenk, this volume), the final state being the so called $4 \pi$-detectors. The potential of magnetic scattering of neutrons to measure magnetic textures has virtually not even been recognized. Finally, the theoretical consideration and experimental measurement of various kinds of generalized textural quantities is still at its beginning. It is hoped that this development finally leads to a statistically complete description of the polycrystalline state of polyphase materials allowing the theoretical deduction of the properties of these materials from the properties of the constitutive crystals and the generalized textural variables. Until this goal is reached the field of textures will continuously attract the attention of materials scientists and engineers as well as earth scientists at least for the next fifty years.

\section{References}

Abbruzzese, G. and Lücke, K. (1986). Acta Met. 34, 905-914.

Abe, T. and Nagaki, S. (1981). Proceedings 2nd Intern. Ris $\varnothing$ Symp. 125-130. 
Adams, B. L., Morris, P. R., Wang, T. T., Willden, K. S. and Wright, S. I. (1987). Acta Met. 35, 2935-2946.

Barral, M., Lebrun, J. L., Sprauel, J. M. and Maeder, G. (1987). In: Theoretical Methods of Texture Analysis Ed. H. J. Bunge, DGM Informationsgesellschaft Oberursel 355-364.

Beck, P. A. (1951). Trans. AIME 191, 474-476.

Berveiller, M., Hiki, A. and Zaoui, A. (1981). Proceedings ICOTOM 6 Tokyo 452-461.

Bishop, J. F. W. and Hill, R. (1951). Phil. Mag. 42, 414-427.

Bleck, W. and Bunge, H. J. (1981). Acta Met. 29, 1401-1412.

Bordas, J., Glazer, A. M., Howard, C. J. and Bourdillon, A. J. (1977). Phil. Mag. 35, 311-323.

Born, E. (1979). Kristall u. Technik 15, 325-332.

Brakman, C. M. (1987). In: Theoretical Methods of Texture Analysis. Ed. H. J. Bunge, DGM Informationsgesellschaft Oberursel 377-392.

Brokmeier, H. G. (1983). Texturuntersuchungen an naturlichen und experimentell verfestigten Halit-Gesteinen mit Neutronen und WK-Strahlung. Thesis Clausthal.

Brokmeier, H. G., Böcker, W. and Bunge, H. J. (1988). Proceedings ICOTOM 8 Santa Fe (in print).

Bunge, H. J. (1965). Z. Metallkunde 56, 872-874.

Bunge, H. J. (1966). Kristall u. Technik 1, 177-173.

Bunge, H. J. (1967). Z. Metallkunde 58, 649-657.

Bunge, H. J. (1968). Kristall u. Technik 3, 431-438.

Bunge, H. J. (1969). Mathematische Methoden der Texturanalyse. Akademie Verlag Berlin.

Bunge, H. J. (1970). Kristall u. Technik 5, 145-175.

Bunge, H. J. (1982). Texture Analysis in Material Science. Butterworth Publ. London.

Bunge, H. J. (1982). Z. Metallkunde 73, 483-488.

Bunge, H. J. (1985a). Z. Metallkunde 76, 92-101.

Bunge, H. J. (1985b). Z. Metallkunde 76, 457-470.

Bunge, H. J. (1987a). International Materials Review 32, 265-291.

Bunge, H. J. (1987b). Proceedings 8th Intern. Ris $\emptyset$ Symp. 55-66.

Bunge, H. J. (1988). Proceedings ICOTOM 8 Santa Fe (in print).

Bunge, H. J. and Dahlem, E. (1986). Proceedings 7th Risø Intern. Symp. 225-260.

Bunge, H. J., Dahms, M. and Brokmeier, H. G. Crystallography Reviews (in print).

Bunge, H. J. and Esling, C. (1979). Journ. de Physique Lettres 40, 627-628.

Bunge, H. J. and Esling, C. (1981). J. Appl. Cryst. 14, 253-255.

Bunge, H. J. and Esling, C. (Eds.) (1982). Quantitative Texture Analysis. DGM Informationsgesellschaft, Oberursel.

Bunge, H. J. and Esling, C. (1984). Scripta Met 18, 191-195.

Bunge, H. J. and Esling, C. (1985). Acta Cryst. A41, 59-67.

Bunge, H. J., Esling, C. and Muller, J. (1981). Acta Cryst. A37, 889-899.

Bunge, H. J., Humbert, M. and Welch, P. I. (1983). Scripta Met 17, 1403-1405.

Bunge, H. J. and Leffers, T. (1971). Scripta Met 5, 143-149.

Bunge, H. J., Liu, Y. S. and Hanneforth, R. (1987). Scripta Met 21, 1423-1427.

Bunge, H. J. and Nauer-Gerhardt, C. U. (1986). In: Experimental Techniques of Texture Analysis. Ed. H. J. Bunge. DGM Informationsgesellschaft, Oberursel 147-154.

Bunge, H. J. and Plege, B. (1986). Proceedings 7th Ris $\varnothing$ Intern. Symp. 255-260.

Bunge, H. J. and Tobisch, J. (1968). Z. Metallkunde 59, 471-475. 
Bunge, H. J., Wagner, F., Welch, P. I. and van Houtte, P. (1985). Journ. de Physique Lettres 46, 1109-1113.

Bunge, H. J. and Weiland, H. (1988) Textures and Microstructures 7, 231-263.

Bunge, H. J., Wenk, R. and Pannetier, J. (1982). Textures and Microstructures 5, 153-170.

Burgers, W. G. and Louwers, P. C. (1931). Z. Physik 61, 605.

Canova, G. R. and Kocks, U. F. (1984). Proc. ICOTOM 7 Noordwijkerhout 573-579.

Chen, J. W. and Bowman, U. J. (1988). Proceedings ICOTOM 8 Santa Fe (in print).

Chin, A. and Gould, R. D. (Eds.) (1984). Texture-Microstructure-Mechanical Properties Relationships of Materials. The Metallurgical Society of AIME, Metals Park.

Chin, G. Y. (1969). In: Textures in Research and Practice Ed. J. Grewen and G. Wassermann Springer Verlag Berlin 51-80.

Chin, G. Y., Hosford, W. F. and Mendorf, D. R. (1969). Proc. Roy. Soc. A309, 433-456.

Clement, A. and Coulomb, P. (1979). Scripta Met 13, 899-901.

Dahms, M. and Bunge, H. J. (1986). In: Experimental Techniques of Texture Analysis. Ed. H. J. Bunge. DGM Informationsgesellschaft Oberursel 371-378.

Dahms, M. and Bunge, H. J. (1987). In: Theoretical Methods of Texture Analysis Ed. H. J. Bunge, DGM Informationsgesellschaft Oberursel 143-158.

Dahms, M. and Bunge, H. J. (1988a). Textures and Microstructures (in print).

Dahms, M. and Bunge, H. J. (1988b). Proceedings ICOTOM 8 Santa Fe (in print).

Dahms, M. and Bunge, $H$. J. This volume.

Davies, G. J. and Bateman, R. M. (1981). Proceedings ICOTOM 6 Tokyo 132-148.

Decker, B. F., Asp, E. T. and Harker, J. (1948). J. Appl. Phys. 19, 388-392.

Doherty, R. D. (1978). In: Recrystallization of Metallic Materials. Ed. F. Haessner. Dr. Riederer Verlag Stuttgart 23-62.

Drechsler, L. P., Feldmann, K., Frischbutter, A. and Walther, K. This volume.

Esling, C., Bechler-Ferry, E. and Bunge, H. J. (1982). Textures and Microstructures 5, 95-125.

Esling, C., Bunge, H. J. and Muller, J. (1980). Journ. de Physique Lettres 41, $542-545$.

Esling, C., Bunge, H. J., Phillippe, M. J. and Muller, J. (1987). In: Theoretical Methods of Texture Analysis Ed. H. J. Bunge. DGM Informationsgesellschaft Oberursel 105-126.

Feldmann, K. (1986). In: Experimental Techniques of Texture Analysis. Ed. H. J. Bunge, DGM Informationsgesellschaft Oberursel 253-264.

Friedrich, W., Knipping, P. and Laue, M. v. (1912). Bayer. Akad. Ber. 303.

Gil Sevillano, J., van Houtte, P. and Aernoudt, E. (1980). Large Strain Work Hardening and Textures. Progress in Material Science 25, 69-412.

Gonell, H. W. and Kratky, O. (1931). Handbuch der physikalisch-technischen Mechanik IV Leipzig 286-318.

Grewen, J. and Wassermann, G. (1955). Acta Met. 3, 354-360.

Haessner, F., Jakubowski, U. and Wilkens, (1966). M. Trans. Met. Soc. AIME 236, 228-230.

Haessner, F. and Hofmann, S. (1978). In: Recrystallization of Metallic Materials. Ed. F. Haessner. Dr. Riederer Verlag Stuttgart 63-96.

Haessner, F. (1981). Proceedings ICOTOM 6 Tokyo 223-238.

Heimendahl, M. v. (1970). Einfuhrung in die Elektronenmikroskopie, Vieweg. 
Heimke, G. (1976). Keramische Magnete, Springer Verlag Wien.

Hirsekorn, S. (1987). In: Theoretical Methods of Texture Analysis. Ed. H. J. Bunge, DGM Informationsgesellschaft Oberursel 365-376.

Honeff, H. and Mecking, H. (1978). Proceedings ICOTOM 5 Aachen 265-275.

Humphreys, F. J. (1983). Textures and Microstructures 6, 45-62.

Imhof, J. (1977). Z. Metallkund 68, 38-43.

Jansen, E., Schaefer, W. and Will, G. (1986). In: Experimental Techniques of Texture Analysis. Ed. H. J. Bunge, DGM Informationsgesellschaft Oberursel 229-240.

Kallend, J. S. and Davies, G. J. (1972). Textures and Microstructures 1, 51-70.

Kern, R. (1984). Practical Metallography 21, 273-293.

Klein, H., Esling, C. and Bunge, H. J. (1987). Proceedings 8th Risø Intern. Symp. 379-386.

Knipping, P. (1913). Physikalische Zeitschrift 14, 996.

Kopineck, H. J. (1986). In: Experimental Techniques of Texture Analysis. Ed. H. J. Bunge. DGM Informationsgesellschaft Oberursel 171-182.

Kröner, E. (1958). Z. Phys. 151, 504-518.

Kröner, E. (1961). Acta Met. 9, 155-162.

Kröner, E. (1974). In: Mechanische Anisotropie. Hrsg. H. P. Stüwe, Springer Verlag Wien 149-176.

Leffers, T. (1968). Phys. Stat. Sol. 25, 337-344.

Liang, Z., Wang, F. and Xu, J. (1988). Proc. ICOTOM 8 Santa Fe (in print).

Lücke, K., Perlwitz, H. and Pitsch, W. (1964). Phys. Stat. Sol. 7, 733-746.

Lücke, K., Pospiech, J., Virnich, K. H. and Jura, J. (1981). Acta Met. 29, 167-185.

Matsuo, M., Tani, S. and Hayami, S. (1972). Acta Cryst. A28, 233.

Matthies, S. (1979). Phys. Stat. Sol. (b) 92, K. 135-138.

Matthies, S. (1982). Aktuelle Probleme der quantitativen Texturanalyse. Zentralinstitut für Kernforschung Rossendorf.

Matthies, S. (1988). Proceedings ICOTOM 8 Santa Fe (in print).

Matthies, S. and Vinel, G. W. (1982). Phys. Stat. Sol. B112, K111-115.

Matthies, S., Vinel, G. W. and Helmig, K. (1987). Standard Distributions in Texture Analysis. Akademie-Verlag Berlin.

Maurer, R. This volume.

Merchant, H. D. and Morris, J. G. (1985). (Eds) Textures in Non-Ferrous Metals and Alloys. The Metallurgical Society of AIME, Metals Park.

Mori, M., Ishida, Y. and Onoe, M. (1982). Electron Microscopy 1982, Proc. 10th Intern. Congr. Electron Microscopy Hamburg Vol. 2, 123-124.

Morris, P. R. (1970). Int. Eng. Sci. 8, 49-61.

Morris, P. R., Wang, T. T. and Adams, B. L. (1988). Proceedings ICOTOM 8 Santa $\mathrm{Fe}$ (in print).

Nauer-Gerhardt, C. U. and Bunge, H. J. (1988). Proceedings ICOTOM 8 Santa Fe.

Novikov, V. Ju (1976). Texture of Crystalline Solids 1, 35-44.

Ord, A. (1988). Proceedings ICOTOM 8 Santa Fe (in print).

Ortel, G. (1985). In: Preferred Orientation in Deformed Metals and Rocks. Ed. H. R. Wenk. Academic Press Orlando 259-266.

Plege, B. (1983). Zur Entstehung der Primärrekristallisationstextur von CuZn-30 Blechen. Thesis Clausthal.

Plege, B. (1986). In: Experimental Techniques of Texture Analysis. Ed. H. J. Bunge, DGM Informationsgesellschaft, Oberursel 315-330.

Puch, K. H., Klein, H. and Bunge, H. J. (1984). Z. Metallkunde 75, 133-139.

Quade, $H$. This volume. 
Roe, R. J. (1965). J. Appl. Phys. 36, 2024-2031.

Ruer, D. and Baro, R. (1977). Adv. X-ray Anal. 20, 187-200.

Sander, B. (1930). Gefügeregelung der Gesteine. Springer Verlag Wien.

Schläfer, D. (1968). Kristall u. Technik 3, 473-476.

Schulz, L. G. (1949). J. Appl. Phys. 20, 1030-1033.

Schwarzer, R. (1982) Z. Metallkunde 73, 495-498.

Schwarzer, R. (1983). Beitr. elektron. Direktabb. Oberfl. 16, 131-134.

Schwarzer, R. and Weiland, H. (1984). Proceedings ICOTOM 7 Noordwijkerhout 839-843.

Schwarzer, R. and Weiland, H. (1988). Proceedings ICOTOM 8 Santa Fe (in print).

Taylor, G. I. (1938). J. Inst. Metals 62, 307-324.

van Houtte, P. (1983). Textures and Microstructures 6, 1-20.

Venables, J. A. and Bin-Jaya, R. (1977). Phil Mag 34, 1317-1332.

Vergamini, Ph. J. and Wenk, H. R. This volume.

Wassermann, G. (1939). Texturen metallischer Werkstoffe Springer Verlag Berlin.

Wassermann, G. and Grewen, J. (1962). Texturen metallischer Werkstoffe II. Aufl. Springer Verlag Berlin.

Weiland, H. and Schwarzer, R. (1986). In: Experimental Techniques of Texture Analysis. Ed. H. J. Bunge, DGM informationsgesellschaft Oberursel 301-313.

Weissenberg, K. (1922). Ann. Phys. 69, 409-435.

Wenk, H. R. (Ed.) (1985). Preferred Orientation in Deformed Metals and Rocks. Academic Press Orlando.

Wenk, H. R. et al. (1988). Proceedings ICOTOM 8 Santa Fe (in print).

Wenk, H. R. and Kocks, U. F. (1987). Met. Trans. A18, 1083-1092.

Wever, F. (1924). Z. Phys. 28, 69-90.

Williams (1968). Trans. Met. Soc. AIME 242, 104-115. 